\title{
Exploring knowledge, perceptions and attitudes about generic medicines among final-year health science students
}

\author{
V Bangalee, BPharm, MPharm; N Bassa, BPharm; J Padavattan, BPharm; A R Soodyal, BPharm; F Nhlambo, BPharm; K Parhalad, BPharm; \\ D Cooppan, BPharm
}

Discipline of Pharmaceutical Sciences, School of Health Sciences, University of KwaZulu-Natal, Durban, South Africa

Corresponding author: V Bangalee (bangalee@ukzn.ac.za)

\begin{abstract}
Background. The use of generic medicines to reduce healthcare costs has become a mandated policy in South Africa. An increase in the use of generics can be achieved through improved knowledge, attitudes and perceptions of generic medicine among healthcare professionals.

Objective. To explore knowledge, attitudes and perceptions among final-year health science students on generic medication.

Methods. A cross-sectional survey was carried out among the final-year audiology, dental therapy, pharmacy, physiotherapy, occupational therapy, optometry, speech-language and sport science students enrolled at the University of KwaZulu-Natal. A questionnaire was used as the study tool, developed using information adapted from literature reviews. Data analysis was completed using Statistical Package for the Social Sciences (SPSS) version 21, and computed using descriptive statistics.

Results. Total number of participants was 211 , as follows: audiology ( $n=14)$, dental therapy $(n=15)$, pharmacy ( $n=81)$, physiotherapy ( $n=41)$, occupational therapy $(n=6)$, optometry $(n=25)$, speech-language $(n=6)$ and sport science $(n=23)$. A total of $90.0 \%$ of students had heard of generic medicines, with $20.9 \%$ of them agreeing that generic medicines are less effective than brand-name medicines. Concerning safety, 30.4\% believed that brand-name medicines are required to meet higher safety standards than generic medicines. Regarding the need for information on issues pertaining to safety and efficacy of medicines, $53.3 \%$ of participants felt that this need was not being met.

Conclusion. All groups had knowledge deficits about the safety, quality and efficacy of generic medicines. The dissemination of information about generic medicines may strengthen future knowledge, attitudes and perceptions.
\end{abstract}

Afr J Health Professions Educ 2016;8(1):56-58. DOI:10.7196/AJHPE.2016.v8i1.560

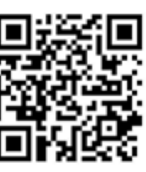

Drugs play a central role in ensuring the successful health of any population, and this holds equally true for South Africa (SA), which is currently grappling with a high burden of disease. Since the abolition of apartheid, the SA healthcare system has undergone drastic reform, with one of the main priorities being to ensure the availability and affordability of quality healthcare for all citizens. ${ }^{[1]}$ In 2001, the SA government amended the Medicines and Related Substances Act 101 of 1965, obligating pharmacists to inform all patients of the benefits of generic medicine substitution. ${ }^{[2]}$ The shift in legislation to increase the use of generic drugs was primarily instituted as a means of reducing healthcare expenditure for both patients and government. In the discussion over the use of generic medicines, prescriber and dispenser perceptions have often been neglected. Several international studies have noted the influence of healthcare professionals on the consumption of generic medicines; however, very little knowledge on the SA perspective has been previously researched. ${ }^{[3,4]}$

Generic medicines are the therapeutic equivalents of proprietary, branded or innovator medicines..$^{[5]}$ They are of the same strength and dosage form, and possess the same safety and efficacy profiles, as the equivalent innovator medicines ${ }^{[3]}$ The primary difference is that generic medicines are much more cost effective than the innovator medicine. The sustainability of the generic medicine sector is vital, to ensure that its role in increasing accessibility and affordability of essential treatments will extend well into the future.

Multiple factors contribute to generic medicine use, among them providerlevel factors such as pharmacist and prescribing-doctor beliefs or practices. Despite the several advantages offered by the use of generic medicines, the perceptions, attitudes and beliefs held by healthcare practitioners have been identified as a potential barrier to the use of generic medicines. ${ }^{[6]}$ Furthermore, once practice habits have been embedded, it may prove difficult to change the prescriber and dispensing practices of healthcare providers, which highlights the importance of correcting misconceptions before the commencement of professional practice.

Based on the nature of their future jobs, healthcare professionals will have an effect on their patients' medication choices. It is, therefore, essential to evaluate future practitioners' knowledge and perceptions of generic medicines. The findings of this study will help to address any misunderstandings that these students may have about generic medicines at this crucial stage of their professional career, and aid universities in altering curricula to improve student understanding.

\section{Method Study sample}

A cross-sectional survey was conducted among the final-year audiology, dental therapy, pharmacy, physiotherapy, occupational therapy, optometry, speech-language and sport science students enrolled at the University of KwaZulu-Natal (UKZN), Durban, SA. Convenience sampling was adopted to approach potential respondents.

\section{Ethical considerations}

Gatekeeper permission and ethical approval for this study were obtained from UKZN Faculty of Health Sciences Ethics Committee (Ref. SHSEC 006/14). Written consent was obtained from the respondents who participated in the study. Any information disclosing respondent identity was excluded from the tool.

\section{Data analysis}

Descriptive statistics were completed using SPSS version 21 (IBM, USA). 


\section{Study tool}

A questionnaire was developed to obtain the objectives of the study. The questionnaire was subdivided into four sections and was developed after reviewing the available published literature in the area. The first section consisted of four demographic questions about age, gender, discipline and work experience. A 5-item Likert-type scale was used to record variations in perceptions, attitudes and knowledge, constituting the remaining three sections. The questionnaires were personally distributed and data were collected over a 3-week period.

\section{Results}

Table 1 illustrates the demographics and general knowledge about generic medications of the respondents in the study. A total of 211 students (52 males and 155 females) completed the survey, with the majority of students $(65.0 \%)$ aged

Table 1. Respondent demographics and general knowledge about generic medications

\begin{tabular}{|c|c|}
\hline Demographics and knowledge & Frequency, $n$ \\
\hline \multicolumn{2}{|l|}{ Groups } \\
\hline Audiology & 14 \\
\hline Speech-language & 6 \\
\hline Dental therapy & 15 \\
\hline Occupational therapy & 6 \\
\hline Optometry & 25 \\
\hline Pharmacy & 81 \\
\hline Physiotherapy & 41 \\
\hline Sport science & 23 \\
\hline \multicolumn{2}{|l|}{ Age (years) } \\
\hline $18-20$ & 15 \\
\hline $21-22$ & 133 \\
\hline $23-25$ & 52 \\
\hline$>25$ & 6 \\
\hline \multicolumn{2}{|l|}{ Gender } \\
\hline Male & 52 \\
\hline Female & 155 \\
\hline \multicolumn{2}{|l|}{$\begin{array}{l}\text { Work experience in hospital } \\
\text { or community pharmacy/job } \\
\text { experience }\end{array}$} \\
\hline Yes & 123 \\
\hline No & 88 \\
\hline \multicolumn{2}{|l|}{$\begin{array}{l}\text { Have you ever heard of branded } \\
\text { medicine? }\end{array}$} \\
\hline Yes & 158 \\
\hline No & 53 \\
\hline \multicolumn{2}{|l|}{$\begin{array}{l}\text { Have you ever heard of generic } \\
\text { medicine? }\end{array}$} \\
\hline Yes & 179 \\
\hline No & 32 \\
\hline
\end{tabular}

21 - 22 years. Of these, 14 (6.6\%) were audiology students, 6 (2.8\%) were speech-language, 15 (7.1\%) were dental therapy, $6(2.8 \%)$ were occupational therapy, 25 (11.8\%) were optometry, 81 (38.4\%) were pharmacy, 41 (19.4\%) were physiotherapy and $23(10.9 \%)$ were sport science students. Of the respondents, $68.3 \%$ had previous work experience in a hospital or community pharmacy. Majorities of $79.4 \%$ and $89.5 \%$ of students had heard of branded medicines and generic medicines, respectively.

With regard to student knowledge on generic medicines (Table 2), an overall majority of students knew that generic medicines are interchangeable (74.1\%), must be in the same dosage form $(58.0 \%)$ and are the therapeutic equivalents of brand-name medicines (66.3\%). Only $42.8 \%$ of students were aware that generic medicines are manufactured after patent expiry of originator medicines, with a smaller percentage (19.6\%) agreeing that generic medicines produce more side-effects compared with brand-name medicines.

For perceptions of quality, safety and efficacy of generic medicines (Table 3), the majority of respondents did not associate generic medicines

Table 2. Knowledge of generic medicines recorded according to the Likert scale*

\begin{tabular}{|c|c|c|c|c|c|}
\hline Survey question/statement & 1 & 2 & 3 & 4 & 5 \\
\hline $\begin{array}{l}\text { Generic medicines are interchangeable with brand-name/ } \\
\text { originator medicines, } \%\end{array}$ & 41.6 & 32.5 & 19.1 & 5.3 & 1.4 \\
\hline $\begin{array}{l}\text { A generic medicine must be in the same dosage form (e.g. tablet, } \\
\text { capsule) as the brand-name/originator medicine, } \%\end{array}$ & 37.2 & 20.8 & 23.2 & 14.5 & 3.9 \\
\hline $\begin{array}{l}\text { Generic medicines are therapeutically equivalent to brand-name/ } \\
\text { originator medicines, } \%\end{array}$ & 38.0 & 28.3 & 21.0 & 9.3 & 2.4 \\
\hline $\begin{array}{l}\text { Generic medicines are manufactured after the patent expiry of } \\
\text { originator/innovator, \% }\end{array}$ & 31.4 & 11.4 & 32.4 & 12.9 & 11.9 \\
\hline $\begin{array}{l}\text { Generic medicines produce more side-effects than brand-name } \\
\text { medicines, \% }\end{array}$ & 4.3 & 15.3 & 34.4 & 22.5 & 23.4 \\
\hline
\end{tabular}

Table 3. Perceptions of the quality, safety and efficacy of generic medicines versus brand-name medicines recorded according to the Likert scale*

\begin{tabular}{|c|c|c|c|c|c|}
\hline Survey question/statement & 1 & 2 & 3 & 4 & 5 \\
\hline $\begin{array}{l}\text { Generic medicines are of inferior quality to brand-name } \\
\text { medicines, \% }\end{array}$ & 4.8 & 17.2 & 23.9 & 25.8 & 28.2 \\
\hline Generic medicines are less effective than brand-name medicines, $\%$ & 6.3 & 14.9 & 26.0 & 26.4 & 26.4 \\
\hline Generic medicines are less safe than original medicines, $\%$ & 2.9 & 11.1 & 21.3 & 33.3 & 31.4 \\
\hline $\begin{array}{l}\text { Generic medicines are less expensive than brand-name } \\
\text { medicines, \% }\end{array}$ & 28.2 & 34.9 & 16.7 & 11.0 & 9.1 \\
\hline $\begin{array}{l}\text { Brand-name medicines are required to meet higher safety } \\
\text { standards than generic medicines, } \%\end{array}$ & 11.7 & 19.4 & 29.6 & 16.5 & 22.8 \\
\hline I believe that generic medicines are only meant for the poor, $\%$ & 11.5 & 7.7 & 17.7 & 16.3 & 46.4 \\
\hline
\end{tabular}

Table 4. Perceptions of current university education about generic medicines recorded according to the Likert scale ${ }^{*}$

\begin{tabular}{|c|c|c|c|c|c|}
\hline Survey question/statement & 1 & 2 & 3 & 4 & 5 \\
\hline $\begin{array}{l}\text { I need more information on the issues pertaining to the safety } \\
\text { and efficacy of generic medicines, } \%\end{array}$ & 26.2 & 27.1 & 17.6 & 14.8 & 14.3 \\
\hline $\begin{array}{l}\text { I find it easier to recall a medicine's therapeutic class using } \\
\text { generic names rather than brand names, \% }\end{array}$ & 17.6 & 18.6 & 41.0 & 12.4 & 10.5 \\
\hline $\begin{array}{l}\text { I have been taught how medicines are subsidised in the } \\
\text { Pharmaceutical Benefits Scheme, \% }\end{array}$ & 10.0 & 12.4 & 25.2 & 20.0 & 32.4 \\
\hline
\end{tabular}


with being of inferior quality (22.0\%), being less effective (21.2\%), or being less safe (14.0\%) than brand-name medicines. Overall, $63.1 \%$ of students acknowledged that generic medicines are less expensive than branded medicines. Only $31.1 \%$ of students believed that brand-name medicines are required to meet higher safety standards and a smaller percentage (19.2\%) felt that generic medicines are only meant for the poor.

With regard to the perceptions students had of current university education relating to generic medicines (Table 4 ), $53.1 \%$ of respondents felt that they required more information on the safety and efficacy of generic medicines, with $36.2 \%$ finding it easier to recall a medicine's therapeutic class using generic names rather than brand names. A small percentage thought that they had been taught how medicines are subsidised in the Pharmaceutical Benefit Scheme.

\section{Discussion}

A major responsibility for all educators of health science students is to teach future practitioners about the cost-effective use of medicines. To increase the uptake of generic medicines, it is vital that health science practitioners, in particular pharmacists, have a sound knowledge of the issues surrounding generic medicines.

The current study showed that the majority of students surveyed had heard of branded and generic medicines. A similar finding was observed in a study conducted in Bangladesh, which sought to explore medical and pharmacy students' knowledge and perceptions about generic medicines ${ }^{[5]}$ In our study, however, there was still a significant proportion of students who were unfamiliar with the correct definition of a generic medicine, which came through by incorrect responses to questions on knowledge.

Despite their lower prices, generic medicines are required to meet the same safety standards as brand-name medicines. A majority of participants agreed that generic medicines cost less than brand-name medicines, which provides some promise for the use of generic medicines by these future healthcare practitioners in curtailing patient medication costs.

On perceptions of current university education about generic medicines, a large percentage of students felt that they needed more information on the safety and efficacy of generic medicines, and many students were unfamiliar with the safety standards associated with the regulation of medicines in SA. Similarly, respondents to the study conducted in Bangladesh also displayed concern about the safely and quality of generic medicines.
Lack of or incorrect responses to survey questions may reflect nonexposure to generic medicine issues, differences in professional curricula, or a lack of understanding. In general, mean score differences between the groups showed that pharmacy students' knowledge was better than that of any other group; this probably stems from the limited use and pertinence of medicines in the fields of practice of other students. Future practitioners need to be exposed to these issues early in their education, so that they can be confident in counselling and treating patients whenever applicable.

\section{Limitations}

To our knowledge, the objectives of this study have not been previously researched, which limits comparison of findings with available published literature. The use of convenience sampling, together with the relatively small sample size, might affect the generalisability of the study to the larger student population in SA. Furthermore, the current study did not assess the association between curriculum content and perceptions about the use of generic medicines for each of the chosen disciplines.

\section{Conclusion}

Although there were some differences in the responses received from the different groups of future practitioners, all groups demonstrated knowledge deficits, especially on specific issues relating to the safety and effectiveness of generic medicines. These areas need to be addressed by educators, to convince students of the value of generic medicines to further strengthen policy initiatives.

Acknowledgements. The authors would like to acknowledge Ms Fikile Nkwanyana for her assistance with the statistical analysis.

\section{References}

1. Department of Health. National Drug Policy for South Africa. Pretoria: Government Printer, 1996 2. Government Gazette. General regulations in terms of the Medicines and Related Substances Act, 1965, as amended. Vol. 432, No. 22235. Republic of South Africa, 2001

3. Shrank WH, Stedman M, Ettner SL, et al. Patient, physician, pharmacy, and pharmacy benefit design factors related to generic medication use. J Gen Intern Med 2007;22(9):1298-1304. [http://dx.doi.org/10.1007/s11606007-0284-3]

4. Mott DA, Cline RR. Exploring generic drug use behavior: The role of prescribers and pharmacists in the opportunity for generic drug use and generic substitution. Med Care 2002;40(8):662-674. [http://dx.doi. org/10.1097/00005650-200208000-00006

5. Siam MKS, Khan A, Khan TM. Medical and pharmacy students' knowledge and perceptions about generic medicines in Bangladesh. J Pharm Health Serv Res 2013;4(1):57-61. [http://dx.doi.org/10.1111/jphs.12008] 6. Patel A, Gauld R, Norris P, Rades T. Quality of generic medicines in South Africa: Perceptions versus reality - A qualitative study. BMC Health Serv Res 2012;12(1):297. [http://dx.doi.org/10.1186/1472-6963-12-297] 